\title{
Some Effects of Chronic Gamma Irradiation on Mouse Testis'
}

\author{
B. R. Nebel, E. M. Coulon and D. J. MeWhinnie \\ Division of Biological and Medical Research, Argonne National Laboratory, \\ Argonne, Illinois, U.S. A.
}

Received August 20, 1962

\section{Introduction}

In the late 1940's Lorenz and his colleagues carried out chronic gamma experiments on mice and established the presence of a marked intensity effect on testis weights and spermatogenesis (Lorenz and Eschenbrenner 1947, Eschenbrenner, et al. 1948, Eschenbrenner and Miller 1950). The Lorenz group described the effects of $1.1,4.4$ and $8.8 \mathrm{r}$ per day. Over 16 months the 1.1 and $4.4 \mathrm{r}$ per day series were not different from the controls in relative frequencies of all cell types observed. With $8.8 \mathrm{r}$ per day a difference occurred after 4 months. Multiplication of spermatogonia was reported delayed. Testis weights for $1.1 \mathrm{r}$ per day showed only doubtful depression. With 4.4 and $8.8 \mathrm{r}$ per day there was an initial sharp decrease in testis weight over the first 2 to 4 months, but thereafter there was no appreciable change, the curves for the two exposure rates leveling off at distinctly different values. The authors called attention to the tubular shrinkage but presented no data.

Kohn and his coworkers established that testis weight is an excellent indicator of irradiation damage (Kohn and Kallman 1954, 1955, 1956, Kohn 1955, Kohn et al. 1957). They concluded that weight decrease in the testis depends on one primary event, namely, action on the spermatogonia. In Kohn's experiments fractionation of the dose into 2 to 5 exposures within 1-4 days showed an effect equal to a total unfractionated dose.

The work of Leblond and his group on normal, untreated rat, mouse, hamster and guinea pig testis and that of Oakberg on the mouse testis laid a foundation of accurate quantitative analysis of spermatogenesis under irradiation (Leblond and Clermont 1952a, b, Clermont and Perey 1957, Clermont et al. 1959, Oakberg 1956a, b, 1957b). Oakberg also described the effects of acute irradiation on various spermatogenic elements in the mouse testis (Oakberg 1955a, b, 1957, 1959 and 1960a). The intensive work of A. P. and G. W. Casarett (1957) on rats presents a detailed study of an acute exposure of $324 \mathrm{r}$ compared with a chronic series of $325.8 \mathrm{r}$ given at $3.26 \mathrm{r}$ per day. In the work of the Casaretts as well as that of the Lorenz group and also in some recent work by Ronichevskaya (1959) it is shown that under doses between 3 and $8.8 \mathrm{r}$ per day there is an initial steep decrease in sper-

\footnotetext{
1 This work performed under the auspices of the U.S. Atomic Energy Commission.
} 
matogenesis which then levels off or stabilizes at levels specific for the respective intensity in spite of continued irradiation.

Other recent papers dealing with specific events after acute and chronic irradiation will be mentioned in the discussion. The reader is also referred to Oakberg's $(1956 \mathrm{a}, 1959)$ evaluations of contemporary work and to the papers of Nebel and Murphy (1960) and Nebel, et al. (1960).

\section{Materials and methods}

The data presented in this paper are based on 5 series of sacrifices from the chronic gamma experiment initiated at the Argonne National Laboratory in 1955 (Sacher et al. 1955). Although a vast amount of data was harvested from this experiment we have only concerned ourselves with the effects on the testes, and we have evaluated only four of the many exposure series.

\section{Animals}

The animals used were $\mathrm{LAF}_{1}$ male mice 100 days old at the beginning of the experiment.

\section{Experimental design}

Animals were exposed daily to one of the following doses of gamma irradiation: $0,12,24,43$, and $74 \mathrm{r}$. Three animals from each exposure series were sacrificed at various intervals ranging from 1-500 days after initiation of irradiation.

\section{Experimental procedures}

Irradiation

The mice were housed, 3 per cage, in clear Bakelite cages which were placed on aluminum racks in a low-level gamma exposure room. The source, a 7.8-curie cobalt rod, 12 inches long and $1 / 4$ inch diameter, was raised daily for 12-15 hours. The position of the cages was such that the animals received the daily dose rates already specified.

Autopsy

After the animals were killed by ether inhalation, the testes were removed, weighed, cut in half transversely, fixed in a $20: 2: 1$ mixture of 70 per cent ethanol, formalin, and acetic acid, and embedded in paraffin. Sections were cut at $8 \mu$ parallel to the plane of the original transverse cut and slides were stained in Feulgen-fast green or periodic acid-Schiff.

Measurements

Testis weights. After removal from the animal the testes were trimmed of all extraneous tissue and weighed together on a Gramatic balance.

Testis areas. The area occupied by the cross section of the testis at its greatest diameter was determined with the aid of an ocular micrometer and a stage micrometer. Testes from each animal were measured and the 
mean area calculated from the formula

$$
\operatorname{AREA}=\pi\left[\frac{a+b}{4}\right]^{2}
$$

where $a$ and $b$ are the mean greater and lesser diameters respectively of the testes for each sacrifice group.

Tubule areas. The number of circular and elongate sections of tubules was determined by counting all tubules in the same cross section that was used to measure testis area. Fifteen circular sections were evaluated by measuring the greater and lesser diameter (no tubule being exactly circular). The same measurements were made on 15 elongate tubules. The mean area of the circular tubules is given by

$$
\mathrm{AREA}_{\mathrm{circ}}=c \pi\left[\frac{d+e}{4}\right]^{2},
$$

where $c$ is the number of circulars, $d$ is the average larger diameter of the circulars and $e$ is the average smaller diameter of the circulars. The mean area of the elongate tubules is given by

$$
\mathrm{AREA}_{\mathrm{el}}=\text { fgh , }
$$

where $f$ is the number of elongates and $g$ and $h$ are the average larger and smaller diameters respectively. The total area occupied by the tubules was obtained by summing AREA $_{\text {cire }}$ and AREA $_{\text {el }}$.

Chalkley counts. In order to ascertain the relative distribution of cellular and acellular content in the cross sections, Chalkley (1943) counts were made in the following manner. The controls were grouped into 3 animals each at 5 age levels and 400 "hits" were recorded for each animal. (A hit designates the respective morphological structure which comes to lie under the end of each of the Chalkley pointers.) In the treated series at least 400 " hits" were recorded for each of 27 animals of the $12 \mathrm{r}$ series, and for each of the 18 animals for each of the $24 \mathrm{r}, 43 \mathrm{r}$, and $74 \mathrm{r}$ series. Hits were recorded in the following categories: Sertoli cells, spermatogonia, spermatocytes, spermatids, immature spermatozoa, inner and outer space. The hits on each element were summed, the mean proportions were calculated and standard errors were determined.

Direct counts. Inasmuch as the Chalkley method will tend to miss cells that are present in very low frequency, the Chalkley data were supplemented by direct counts on type $\mathrm{A}$ and intermediate spermatogonia, type $\mathrm{B}$ spermatogonia and leptotene spermatocytes. For the counts of the type $\mathrm{A}$ and intermediate spermatogonia, the testis cross sections of each animal were scanned, 20-60 tubules were randomly selected, and the number of $\mathrm{A}$ and intermediate spermatogonia were recorded. To determine the numbers of 
type B spermatogonia and leptotene spermatocytes, counts were made only in the stages where these cells are present. For example, in scanning the sections, the type B spermatogonia were counted in 30 tubules of spermatogenic stage IV, V or VI. The leptotene spermatocytes were counted in 30 tubules of spermatogenic stage VIII or IX. Most of the data points represent an average of 30 tubules taken from two animals. Inspection of the data shows that the differences between animals were small.

\section{Results}

\section{Testis weights}

After an initial increase due to swelling the testis weights decrease fairly rapidly. This decrease reaches an approximate minimum at the point at

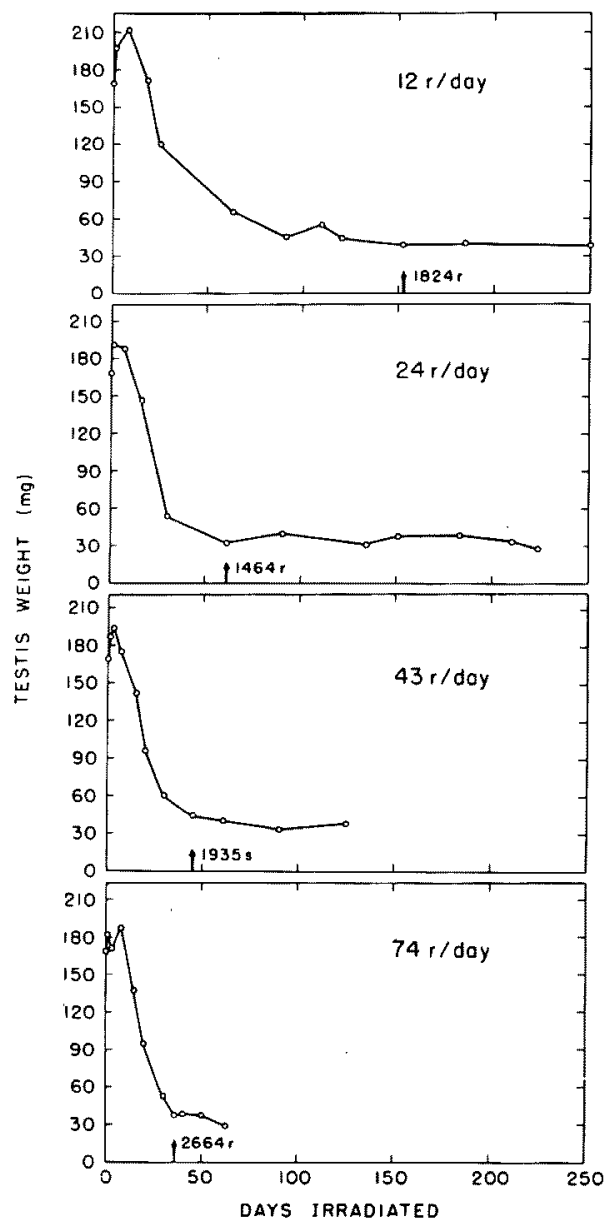

Fig. 1.

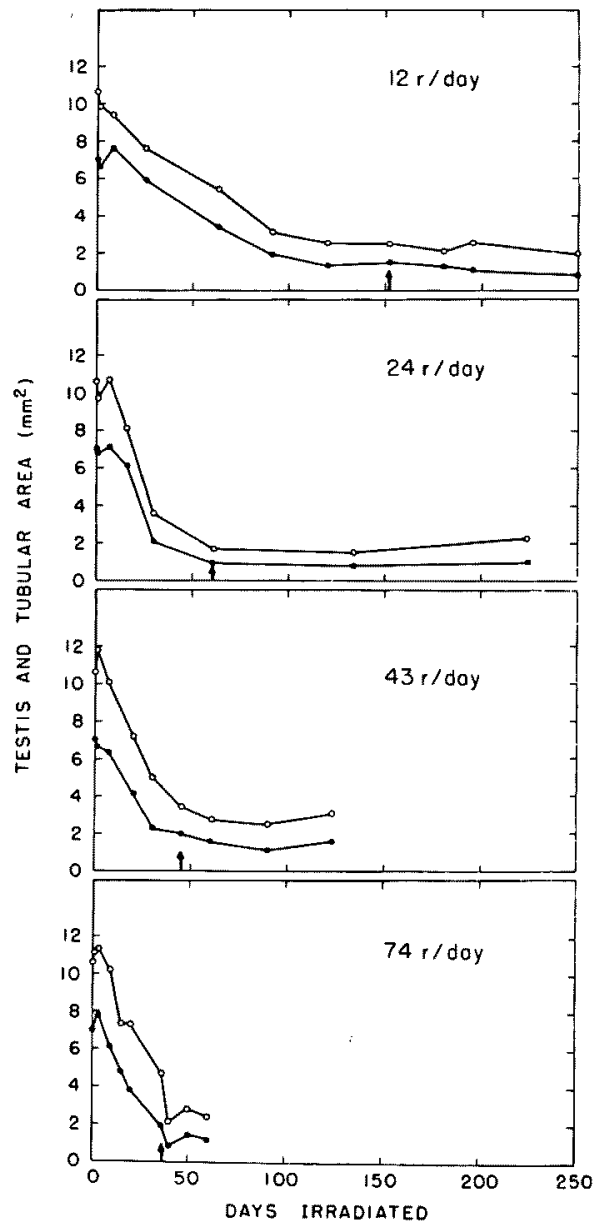

Fig. 2.

Fig. 1. A comparison of the testis weight data for the four series. Testis weights are expressed as the sum of both testes averaged for 3 animals. The arrow represents the point at which less than 1 per cent of the spermatogenic elements remain.

Fig. 2. A comparison of the testicular (open circles) and tubular (closed circles) area data for the four series. The arrow represents the point at which less than 1 per cent of the spermatogenic cells remain. 
which less than $1 \%$ of the spermatogenic cells remain in the tubules (Fig. 1). From that point on the weights remain reasonably constant. The rate of testis weight loss is apparently dependent on effective cumulated dose and independent of time (see discussion). Fig. 1 shows that the cumulated doses are nearly the same at the points at which the 1 per cent level of cellular contents is reached. A biostatistical evaluation of the testis weights will be given in a study of organ weights under chronic ionizing radiation, projected by G. A. Sacher and colleagues.

\section{Testis area}

The pattern of decrease of testis area follows closely that of testis weight. If in Fig. 2 one superimposes an arrow on each group at the point at which less than 1 per cent of spermatogenic cells remain, again it points to that portion of the curve indicating maximum loss. Hence, it is safe to say that irradiation produced cellular loss and the decrease in testis area is closely correlated with this cellular loss and with testicular weight loss.

\section{Tubular area}

From inspection of Fig. 2 it is easily seen that tubular area shows the same pattern of decline as testis area. While this is not surprising it may now be stated with assurance that cellular loss is followed by a decrease in tubular area, which results in a decrease of testis area (and obviously volume) which in turn is associated with a loss in testicular weight.

\section{Chalkley counts}

For these counts the following categories were recorded: Sertoli cells, spermatogonia, spermatocytes, spermatids, immature spermatozoa, inner and outer space. Inner space refers to the area within a tubular cross-section not occupied by cells. Outer space refers to all space outside of tubules and inside of the testis. Leydig cells, blood vessels and extra-tubular substances were scored as outer space. The data are summarized in Table 1.

Sertoli cells

Table 1 (Mean, Sertoli cells) shows that the mean percentage space occupied by Sertoli cells increases with cumulated dose in all four series. At the point of the last Chalkley determination the increase is largest in the 12 r/day series, namely 7.05 times larger than the control value for percentage of Sertoli cells. The factors become progressively smaller for the succeeding series $-5.26,4.81$ and 3.94 for the $24,43,74 \mathrm{r} /$ day respectively. This increase is primarily due to tubular contraction, as suggested by $\mathrm{Nebel}$ and Murphy (1960). Thus, a tubular shrinkage of one-half corresponds to an apparent doubling in the Sertoli cell population. This is substantiated by the fact that at 36 days $(2664 \mathrm{r}$ ) in the $74 \mathrm{r}$ /day series, the Sertoli cell counts have increased by a factor of 3.94 and the tubular area has been reduced to $1 / 3.71$ of the control. While not equally precise when applied to various 


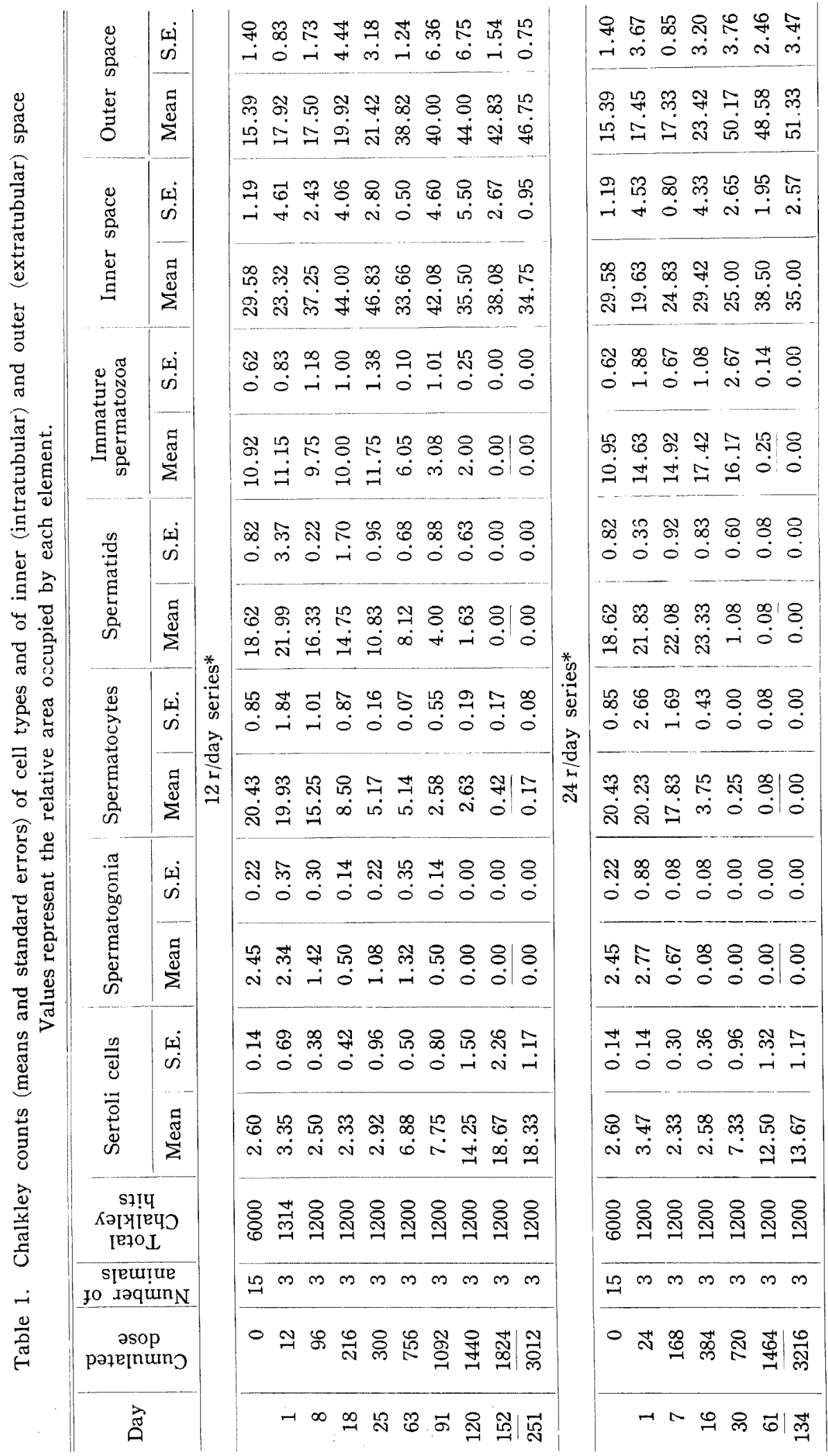




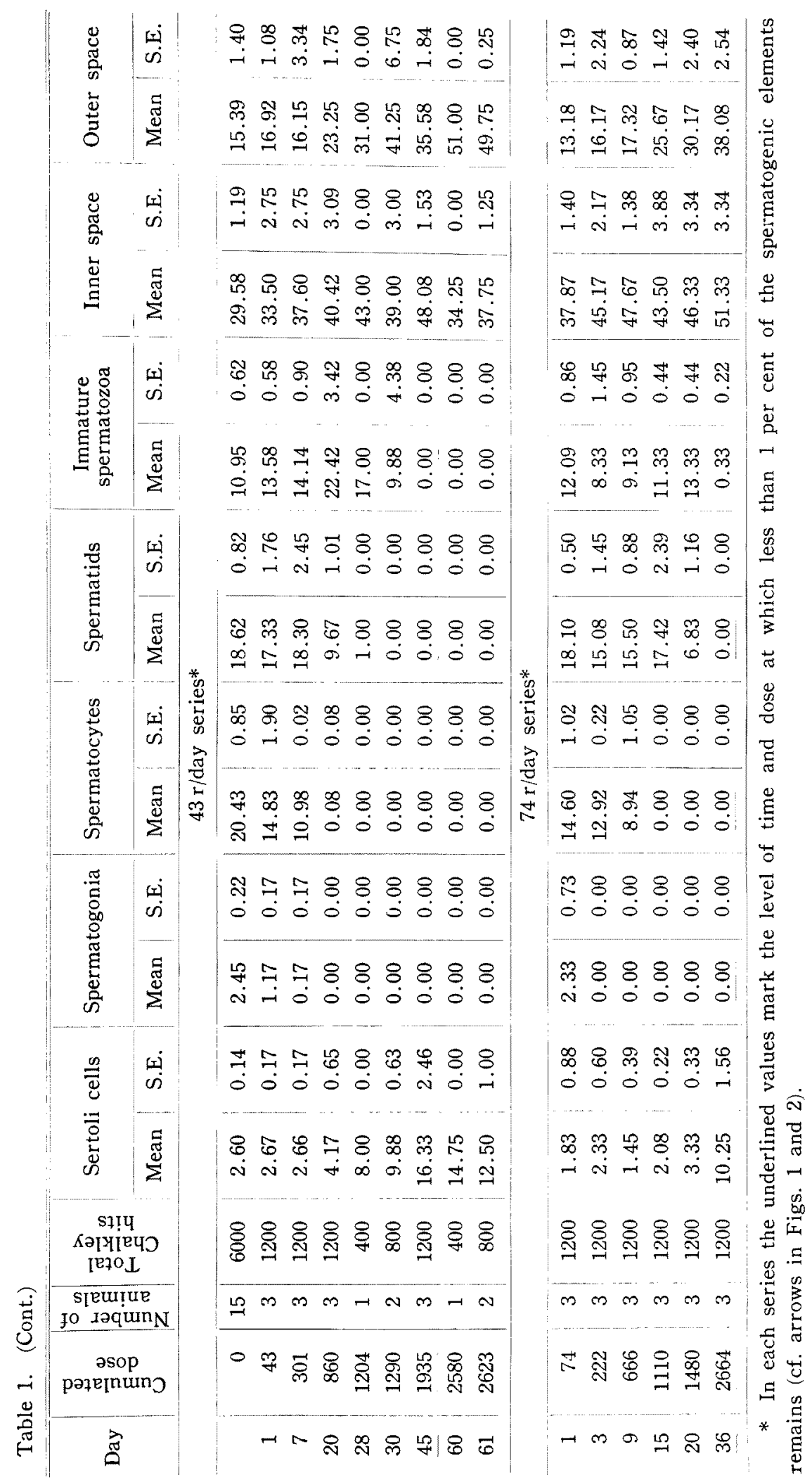


other points, we consider the correspondence satisfactory within the limits of our observations. However in the final stages of tubular degeneration, we have seen Sertoli cells become dislodged and appear in the tubular lumina, apparently being flushed toward the epididymis.

Spermatogonia

Because relatively few spermatogonia were present, their evaluation by the Chalkley methods is not considered satisfactory. The results of the direct counts on these cell types are described below.

Primary spermatocytes

Counts on primary spermatocytes (Table 1) in the four series show very marked differences between the lower and the two higher intensities. Since normal development of spermatocytes requires slightly more than 9 days (Oakberg 1957b), it would be safe to assume that after the supply of type B spermatogonia is cut off, normally developing spermatocytes would gradually disappear, becoming spermatids. This seems essentially true for the 74 and $43 \mathrm{r} /$ day series (see Table 1). Both of these series are compatible with the classical simile of water running out of a reservoir. The counts of the $12 \mathrm{r}$ series indicate that there is considerable elongation of the life span of some spermatocytes. If we assume that the supply was cut off at 25 days or slightly later (cf. Table 2), the presence of spermatocytes at day 120 and even 250 days indicates delayed or arrested development.

Table 2. Direct cell counts (cells per tubule) under chronic irradiation

\begin{tabular}{|c|c|c|c|c|}
\hline Series & Day & $\begin{array}{l}\text { Cumulated } \\
\text { dose, } r\end{array}$ & $\begin{array}{l}\text { Type B spermatogonia } \\
\text { per IV, V, VI tubules }\end{array}$ & $\begin{array}{l}\text { Leptotene spermatocytes } \\
\text { per VIII or IX tubule }\end{array}$ \\
\hline Control & - & 0 & 14.2 & 54.4 \\
\hline $12 \mathrm{r} /$ day & $\begin{array}{r}1 \\
8 \\
18 \\
25 \\
65\end{array}$ & $\begin{array}{r}12 \\
96 \\
216 \\
300 \\
780\end{array}$ & $\begin{array}{r}12.5 \\
8.0 \\
2.9 \\
1.8 \\
0.0\end{array}$ & $\begin{array}{c}52.9 \\
44.3 \\
9.3 \\
13.1 \\
4 \text { tubules/100 have a } \\
\text { few leptotene }\end{array}$ \\
\hline $24 \mathrm{r} / \mathrm{day}$ & $\begin{array}{r}1 \\
7 \\
16\end{array}$ & $\begin{array}{r}24 \\
168 \\
384\end{array}$ & $\begin{array}{l}7.5 \\
2.1 \\
0.0\end{array}$ & $\begin{array}{r}51.1 \\
31.9 \\
0.0\end{array}$ \\
\hline $43 \mathrm{r} / \mathrm{day}$ & $\begin{array}{l}1 \\
7\end{array}$ & $\begin{array}{r}43 \\
301\end{array}$ & $\begin{array}{l}5.7 \\
0.0\end{array}$ & $\begin{array}{r}51.3 \\
0.0\end{array}$ \\
\hline $74 \mathrm{r} /$ day & $\begin{array}{l}1 \\
3 \\
9\end{array}$ & $\begin{array}{r}74 \\
222 \\
666\end{array}$ & $\begin{array}{l}6.3 \\
1.4 \\
0.0\end{array}$ & $\begin{array}{r}48.7 \\
56.5 \\
0.0\end{array}$ \\
\hline
\end{tabular}

Spermatids and spermatozoa.

These cell categories show a higher radiation resistance (Oakberg 1960a). Thus, the disappearance of these cells reflects a cutoff in spermatocytes (compare columns Mean "Spermatocytes" and Mean "Spermatids" in Table 1). This is true of all four series. Again the $12 \mathrm{r}$ /day series shows delayed development of the spermatids and spermatozoa. It is notable that the lowest 
dose rate $(12 \mathrm{r} /$ day) shows the greatest effect on developmental rate (see discussion).

Space

The data show that inner and outer space increase in the course of the experiment. The increase in inner space is due to cell death and removal and the increase in outer space is the result of tubular shrinkage.

\section{Direct counts}

Type $\mathrm{A}$ and intermediate spermatogonia

The direct counts of spermatogonia for each of the four series are shown graphically in Fig. 3. The $74 \mathrm{r} /$ day curve plunges precipitously to zero; the

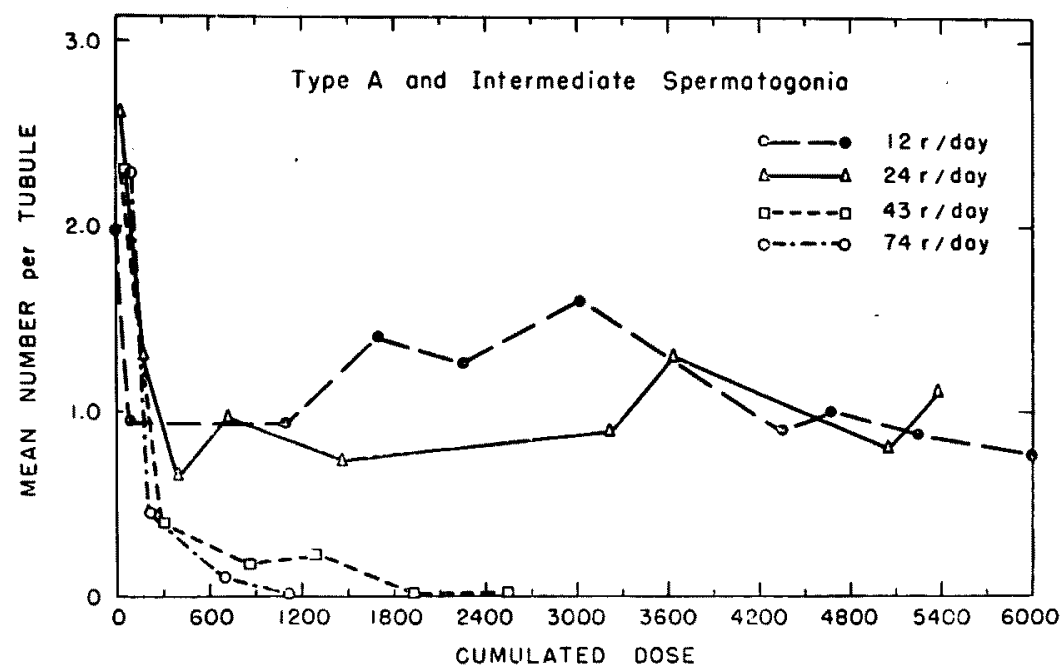

Fig. 3. Survival of the Type $A$ and intermediate spermatogonia in chronically irradiated mice.

$43 \mathrm{r} /$ day curve does the same at about twice the cumulated dose (2000 vs. $1000 \mathrm{r}$ ). The 12 and $24 \mathrm{r} /$ day series never reach zero, the two curves are very similar. From the initial or control values, both decrease by about onethird to one-half but then maintain themselves at a value approximating 50 per cent of the controls.

Type B spermatogonia and leptotene spermatocytes

Since we were interested in studying the disappearance of type B spermatogonia and leptotene spermatocytes, direct counts were made on the control and the four experimental series. According to present views (Oakberg 1955a and 1959) type B spermatogonia should disappear soon after exposure. Their disappearance should be accompanied or followed immediately by the virtual disappearance of leptotene spermatocytes. This was found to be the case as shown in Table 2. 


\section{Discussion}

In 1954 Kohn and Kallman considered testis weight loss in mouse, hamster and rat after radiation. After acute doses ranging between 75 and $900 \mathrm{r}$ these authors concluded that the radiation response includes two components, one covering the steep part of the response curve and the other the second, less steep phase.

We found that even in chronic experiments testis weight loss follows the same general pattern. When we applied their statistical method to our data, we could find no consistent relationship between weight loss and intensity. Thus, Fig. 1 is merely a direct plot of our data. An arrow is placed on each graph at the point at which less than 1 per cent of the spermatogenic elements remain (data from Table 1). It will be noted that each arrow also indicates the approximate point at which the curve seems to attain an asymptotic value. In each series the cumulated dose is very nearly the same at this point ${ }^{1}$. Thus we may conclude that loss of testis weight from irradiation is due directly to a loss of cell contents.

Our data have shown that the apparent increase in the number of Sertoli cells in the irradiated animals is really due to the shrinkage of the tubules. Oakberg (1960a) has independently also used the number of Sertoli cells as an indicator of tubular shrinkage. Sertoli cells appear not to be destroyed by acute irradiation, provided that the dose does not exceed 2000-3000 r. We have observed that under protracted chronic irradiation some Sertoli cells are destroyed. That Sertoli cells are not immortal was also implied by Harding (1961) who found destruction of the young "supporting cells" by acute irradiation not exceeding $430 \mathrm{r}$. Thus the very young and the "very old" continuously overexposed Sertoli cell may succumb. Lacy (1960) has described one of the cyclic functions of the Sertoli nurse cells which consists of the disposal and the reutilization of the Regaud bodies. If radioresistance of the Sertoli cells depends on this metabolism Lacy describes, it seems understandable that in its absence they may approach the other cells in sensitivity.

We have seen that the two lower intensity series show survival of type A spermatogonia apparently at a reduced functional level which represents

1 The relatively great discrepancy in the $74 \mathrm{r} /$ day graph may be explained as follows. The 1 per cent level was determined from the Chalkley data in Table 1. The spermatogenic elements are spermatogonia, spermatocytes, spermatids and immature spermatozoa, and the total percentage for them is found by adding their individual means for any given dosage or day. The underlined values for day, cumulated dose, and cell counts represent the points at which the total first falls below 1 per cent; for the $74 \mathrm{r}$ /day group this occurs at day $36,2664 \mathrm{r}$ cumulated dose. However, the previous point was taken at day 20 (1480 r), and an inspection of Table 1 shows that theoretically the 1 per cent point was reached somewhere between day 20 and day 36 , or between $1480 \mathrm{r}$ and $2664 \mathrm{r}$. This is consistent with our other 1 per cent points of 1824,1464 , and $1935 \mathrm{r}$ for the 12,24 , and $43 \mathrm{r}$ /day series respectively. 
an adaptation to irradiation. Fig. 4 shows a cell of this type in prophase after $5028 \mathrm{r}$. This adaptative phenomenon is receiving increasingly wide recognition. According to Bloom (1950), Warren and Whipple probably deserve credit for the discovery of adaptation in 1923. More recently many similar papers have appeared which deal with adaptation at the cellular level, at the organismal level, and via the nucleus at the genetic level. For some of these effects see Stroud et al. (1955), Sacher (1956), Daquisto (1959), Ronichevskaya (1959), Quastler et al. (1959), Cole (1960), Elkind and Sutton (1960), Maisin et al. (1960), Russell et al. (1960), Whiting (1960), Mole and Thomas (1961), Stearner et al. (1961) and Stroud et al. (1961). Philosophically there is no difference between adaptation under discontinuous dose fractions and chronic continuous or discontinuous irradiation, since repair processes must be assumed to take place during exposure as well as in the intervals between exposures. The complexity of this problem has been treated by Sacher (1958). There is however another factor different from repair

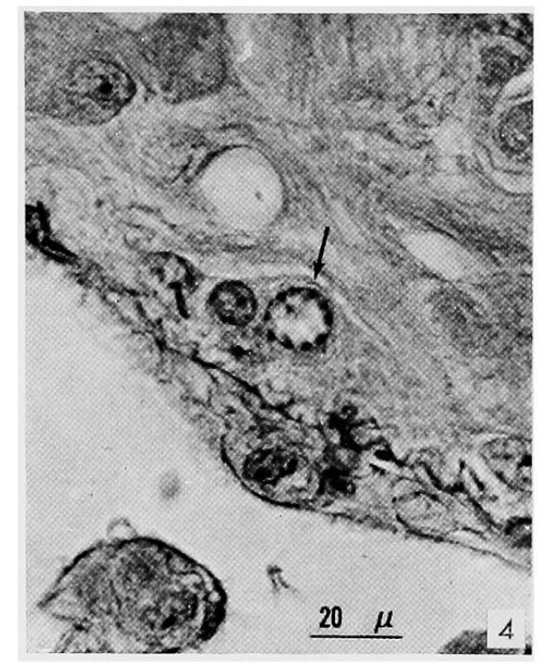

Fig. 4. Spermatogonial cell in prophase from the $12 \mathrm{r}$ /day series at 419 days (cumulated dose, $5028 \mathrm{r}$ ). Apparently two daughter cells, both of which appear to have abnormal nuclei, lie beside the main cell. Fixed in acetic acid : alcohol : formalin, stained with Feulgen and Methyl Green. $\times 1000$.

which enters into adaptation. A change of unknown nature takes place so that one is now dealing with a new system of considerable difference from the one at the outset of the experiment (see Sacher 1956).

Lamerton et al. (1961) studied the effects of chronic gamma irradiation ranging from 415 to $4 \mathrm{r}$ /day in six exposure series on rats. Several different renewal systems were observed. The cells of the gut are reported to show adaptation to $415 \mathrm{r} /$ day after the second day. Such cells appear enlarged and they are labeled more heavily than controls after tritiated thymidine injection.

Does the curve shape of spermatogonial type A death suggest a heterogeneous population? Jones (1960) believes this to be so. Oakberg (1960 a) carefully avoids such terminology suggesting that different mitotic stages might show different sensitivities. Monesi $(1961 \mathrm{a}, \mathrm{b})$ has found clear-cut differences in these sensitivities and in death time, in relation to mitotic stage, for type $A$, intermediate and type $B$ spermatogonia. In type $A$ cells the $G_{1}$ and $S$ phases are relatively short and during these stages sensitivity is high. It is not correct to speak of this as a heterogeneous population. It is a population in which there is a sensitive stage in the normal cycle. 
During the inhibition of mitosis an intracellular change takes place, the result of which we call adaptation. Adaptation decays with time if irradiation is discontinued. Under continuous irradiation there is probably no apparent decay. Unfortunately we do not know what this change consists of. Quastler (1959) has suggested that DNA synthesis may be involved, and possibly polyploidization. While we also have been impressed with the apparent hypertrophy of the nuclei of mitotically delayed type A spermatogonia (Fig. 5) we have not seen polyploid division; Fig. 6 shows a spermatogonial mitosis

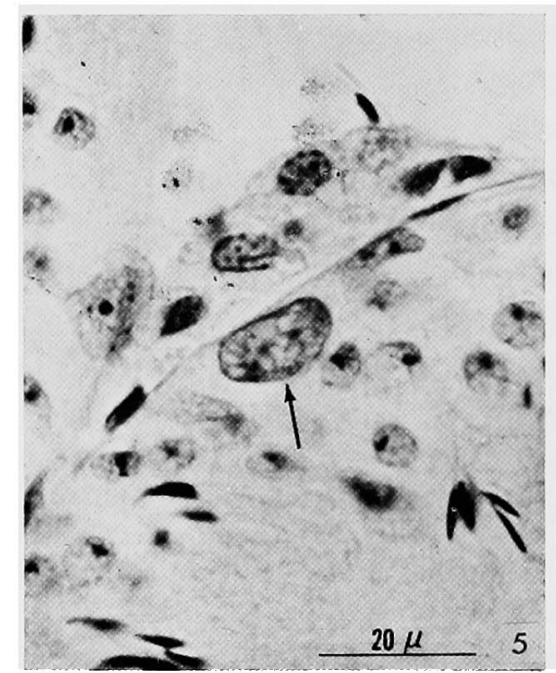

Fig. 5. A hypertrophic type A spermatogonial nucleus from the $74 \mathrm{r} /$ day series after 15 days (cumulated dose, $1110 \mathrm{r}$ ). Fixation and staining same as for Fig. $4 . \times 1000$.

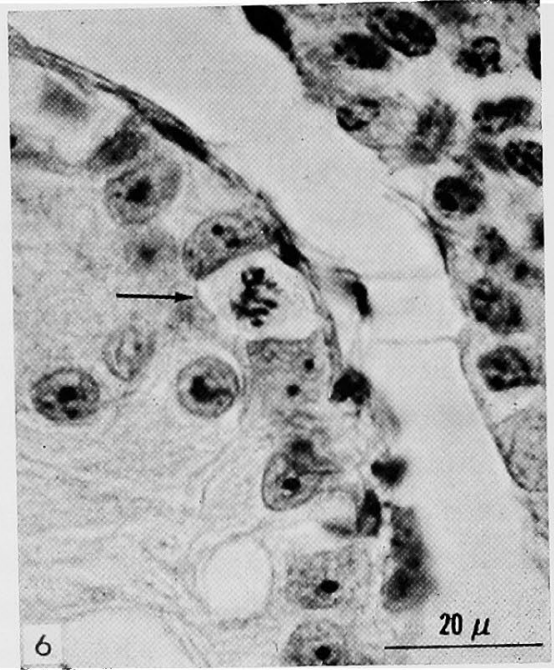

Fig.-6. Spermatogonial mitosis ftera 134 days of $24 \mathrm{r} /$ day (cumulated dose, $3220 \mathrm{r}$ ). This is a metaphase in side view. Fixation and staining same as for Fig. $4 . \times 1000$.

after $3220 \mathrm{r}$. Whitfield and Rixon (1960) have shown that DNA synthesis is not as easily suppressed as mitosis. Oakberg has recently (1959) admitted that mitotic inhibition may modify these cell populations.

Kelly (1961) states that it is important to distinguish between cells dying a reproductive death and those dying in interphase. The former show multihit survival curves with a " $\mathrm{D}_{37}$ " near $100 \mathrm{r}$; the latter show great variation in sensitivity. In spermatogonia "both interphase and reproductive death may be involved". Monesi (1961) has shown Kelly's suggestion to be correct.

Our present observations add nothing to the knowledge that type B spermatogonia are extremely sensitive to irradiation and respond primarily with cell death. For these cells Oakberg (1957a) gives the $\mathrm{LD}_{50}$ for $\mathrm{Co}^{60}$ gamma rays as 20-24 r. There is very little evidence of adaptation in these cell types. It would have to be looked for at very low intensities of chronic exposure.

Table 2 shows that in the $12 \mathrm{r}$ series a few type $\mathrm{B}$ spermatogonia were 
still observed after $300 \mathrm{r}$ (25 days) but were completely absent after that. Leptotene spermatocytes followed the pattern closely. However, after $780 \mathrm{r}$ (65 days) 4 tubules containing some leptotene cells were seen. It is assumed that these represent early spermatocytes in which development has been greatly retarded. This compares well with the Chalkley data of the $12 \mathrm{r}$ series. At the three higher intensity levels the disappearance of type $\mathrm{B}$ spermatogonia and leptotene stages is much faster.

Our leptotene counts confirm the interesting observation that with the onset of meiosis radioresistance increases at least by a factor of 10 (Oakberg 1960a). Thus in the $74 \mathrm{r} /$ day series, after three days, 56.5 cells are seen per stage VIII or IX tubule although the accumulated dose had reached $222 \mathrm{r}$. The much greater apparent drop-off in the $12 \mathrm{r}$ /day series on day $18,216 \mathrm{r}$ accumulated, reflects the fact that leptotene cells from day 8 have now progressed into pachytene. The loss we see is not due to cell death. Thus, our figures clearly show that leptotene is more resistant to radiation and the disappearance of leptotene cells is largely caused by progressive development. Fig. 7 illustrates three types of primary spermatocytes that appear undamaged after $222 \mathrm{r}$.

Oakberg's (1960b) figures suggest an increase in $\mathrm{LD}_{50}$ from $205 \mathrm{r}$ in pre-leptotene to $837 \mathrm{r}$ in diakinesis, using spermatid production as the basis for his $\mathrm{LD}_{50}$ estimates. Oakberg (1960a), using first meiotic anaphase bridges, obtained a " 50 per cent series" with a sensitivity near 1000 in the early stages decreasing to near 200 at diakinesis. Our data are compatible with an average $\mathrm{LD}_{j 0}$ for spermatocytes in prophase of about $500 \mathrm{r}$ as may be seen from the Chalkley data.

Spermatids and spermatozoa may be classified as radioresistant under the conditions of the present experiment. Their loss in numbers is due to progressive development and removal in conjunction with lack of recruitment. While we an-

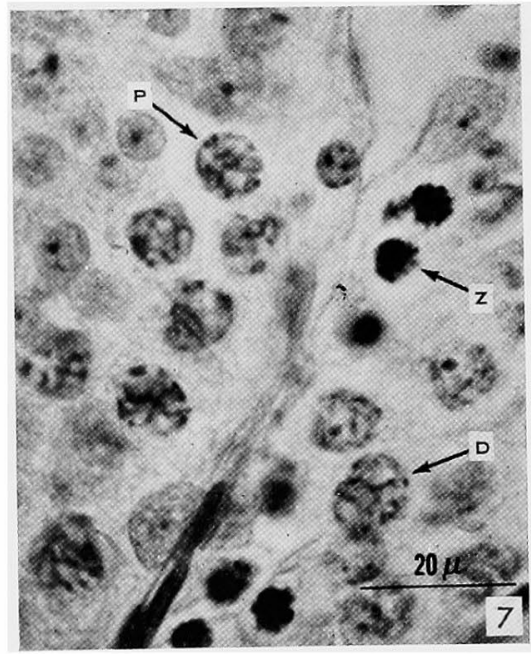

Fig. 7. Primary spermatocytes in pachytene $(\mathrm{P})$ on the left, in zygotene $(\mathrm{Z})$ and diplotene (D) respectively on the right from the $74 \mathrm{r}$ /day series at 3 days (cumulated dose, $222 \mathrm{r}$ ). Fixation and staining same as for Fig. 4. $\times 1000$. alyzed the cross sections for numbers and types of necrotic cells, their incidence was too low to be of any significance.

\section{Summary}

Mice exposed to $12,24,43$ and $74 \mathrm{r}$ gamma radiation per day were observed with reference to the following features and compared with controls : 
testis weights, testis areas in section, tubular areas in section, Chalkley counts on cell types and on empty space within and surrounding the tubules, and special counts of type A and intermediate spermatogonia, type B spermatogonia and leptotene spermatocytes.

The results show that under prolonged gamma irradiation testis weights decrease concomitantly with the loss of spermatogenic cells from the tubules. Measurements of cross sectional areas of testes and tubules were found to decrease along with testis weight. There is an increase in the relative area occupied by Sertoli cells surviving the gamma doses, because of decreasing tubular dimensions. Spermatogonia under 12 and $24 \mathrm{r}$ /day survive with low levels of mitotic activity. At higher intensities they do not survive beyond $2000 \mathrm{r}$ cumulated dose. Spermatocytes vanish due to lack of recruitment as well as through irradiation death. Their disappearance time is intensitydependent. The same is true of spermatids and spermatozoa.

\section{Acknowledgments}

We are most grateful to Dr. S. W. Lesher, Mr. G. A. Sacher, and Mr. A. R. Sallese for their kind assistance and to Mr. S. A. Tyler and Mr. M. H. Dipert for help with statistical evaluations.

\section{References}

Bloom, M. A. 1950. Radiology 55: 104.

Casarett, A. P. and Casarett, G. W. 1957. Univ. Rochester Atomic Energy Project UR $496 / 7$.

Chalkley, H. W. 1943. J. Nat. Cancer Inst. 4: 47.

Clermont, Y. and Perey, B. 1957. Amer. J. Anat. 100: 241.

-, Leblond, C. P. and Messier, B. 1959. Arch. Anat. microscop. et Morphol. exp. 48: 37.

Cole, L. J., Habermeyer, J. G., and Stolan, H. N. 1960. Symposium on the Immediate and Low Level Effects of Ionizing Radiation, Venice 1959. Ed., F. Buzzati (London: Taylor and Francis), p. 361.

Daquisto, M. P. 1959. Radiat. Res. 10: 118.

Elkind, M. M. and Sutton, H. 1960. Radiat. Res. 13: 556.

Eschenbrenner, A. B., Miller, E. and Lorenz,E. 1948. J. Nat. Cancer Inst. 9: 133.

- and - 1950. AMA Arch. Pathol. 50: 730.

Harding, L. K. 1961. Int. J. Rad. Biol. 3: 539.

Jones, E. A. 1960. Int. J. Rad. Biol. 2: 157.

Kelly, L. S. 1961. Brookhaven Symp. in Biol. 14: 32.

Kohn, H. I., and Kallman, R. F. 1954. Brit. J. Radiol. 27: 586; 1955. J. Nat. Cancer Inst. 15: 891; 1956. Radiat. Res. 5: 700.

- 1955. Radiat. Res. 3: 153.

-, Kallman, R. F., Berdjis, C. C. and DeOme, K. B. 1957. Radiat. Res. 7: 407.

Lacy, D. 1960. J. Roy. Microscop. Soc. 79: 209.

Lamerton, L. F. 1961. Brookhaven Symp. in Biol. 14: 158.

Leblond, C. P. and Clermont, Y. 1952a. Amer. J. Anat. 90: 167.

- 1952b, N. Y. Acad. Sci. 55: 4.

Lorenz, E. and Eschenbrenner, A. B. 1947. Fed. Proc. 6: 395.

Maisin, J., Van Duyse, E., Dunjee, A., et al. 1960. Symposium on the Immediate and Low 
Level Effects of Ionizing Radiation, Venice, 1959. Ed., F. Buzzati (London: Taylor and Francis), p. 183.

Mole, R. H. and Thomas, A. M. 1961. Int. J. Rad. Biol. 3: 493.

Monesi, V. 1961. Abstr. Amer. Soc. Zool. (in the press); 1961. Genetics, 46: 884.

Nebel, B. R., Murphy, C. J. and Linder, H. 1960. Radiat. Res. 13: 126.

- and - 1960. Cytologia 25: 244.

Oakberg, E. F. 1955a. Radiat. Res. 2: 369.

- 1955b. J. Morphol. 97: 39.

- 1956a. Amer. J. Anat. 99: 391.

- 1956b. Ibid. 99: 507.

- 1957a. J. Exp. Zool. 134: 343.

- 1957b. Nature 180: 1137.

- 1959. Radiat. Res. 11: 700.

- 1960a. J. Dairy Science 43: 54.

- 1960b. Int. J. Rad. Biol. 2: 196.

Quastler, H., Bensted, J. P., Chir, B., Lamerton, L. F. and Simpson, S. M. 1959. Brit. J. Radiol. 32: 501.

Ronichevskaya, G. M. 1959. Med. Radiol. 4: 34

Russell, W. L., Russell, L. B. and Kelly, E. M. 1960. Symposium on the Immediate and Low Level Effects of Ionizing Radiation, Venice, 1959. Ed., F. Buzzati (London: Taylor and Francis), p. 34.

Sacher, G. A., Grahn, D., Lesher, S., and Hamilton, K. 1955. Semiannual Report of Biological and Medical Research Division. ANL 5378, (Argonne, Illinois: Argonne National Laboratory), p. 91.

- 1956. Radiology 67: 250.

- 1958. Radiation Biolology and Medicine, Ed. W. Claus (Reading: Addison-Wesley Publ. Co.), p. 283.

Stearner, S. P., Tyler, S. A., Sanderson, M. H., and Christian, E. J. B. 1961. Radiat. Res. 14: 732 .

Stroud, A. N., Gurian, J. M., Brues, A. M. and Svoboda, B. R. 1955. Radiat. Res. 2: 267. -, Brues, A. M. and Svoboda, B. R. 1961. Ann. N. Y. Acad. Sci. 95: 942.

Whitfield, J. F. and Rixon, R. H. 1961. Exp. Cell. Res. 19: 531.

Whiting, A. R. 1960. Radiation Protection and Recovery. (London: Pergamon Press) p. 117. 